\title{
Comparative Study of Role of Laparoscopic Vs Conventional Management in Peritonitis
}

\author{
Nishit R Santoki ${ }^{\circ}$, Mahalaxmi Pillai ${ }^{\odot 2}$, Gyaneshwar Rao ${ }^{\circledR 3}$ \\ ${ }^{1}$ Post Graduate Student, Department of Surgery, Gujarat Adani Institute of Medical Science, Bhuj, Gujarat, India, ${ }^{2}$ Assistant Professor, Department of Surgery, Gujarat \\ Adani Institute of Medical Science, Bhuj, Gujarat, India, ${ }^{3}$ Professor and Head, Department of Surgery, Gujarat Adani Institute of Medical Science, Bhuj, Gujarat, India.
}

\section{Abstract}

Background : A very commonly encountered case in the field of general surgery is peritonitis. In our study, we analyse 100 cases of acute peritonitis due to various causes, being managed conventionally and laparoscopicaly. Subjects and Methods: The observational, continuous, prospective, single centre study was carried out at Gujarat Adani Institute of Medical Science at GK General Hospital Bhuj. The study was conducted for a total duration of 27 months from October 2017- December 2019 (Patients were enrolled in the study and followed up till the day of admission to the day of the discharge). Total 100 patients are enrolled in the study but there were no intervention done. We compare the outcomes in terms of postoperative pain, removal of ryles tube, urinary catheter, drains, early ambulation and duration of hospital stay. Results: Maximum patients were diagnosed as having pre pyloric peptic (pyloric with antral perforation) perforation (45\%) followed by jejunal perforation (17\%). successful laparoscopic surgery without conversion was done in $92 \%$. study total 4 cases of laparoscopic managed group needed to convert in open including 2 duodenal perforation cases, 1 sigmoid colon perforation case and 1 ascending colon perforation. Conclusion: Laparascopic intervention to be better of the two provided availability of skill and setup.

Keywords: Hospital stay, Laparoscopic, laparotomy, peritonitis

Corresponding Author: Mahalaxmi Pillai, Assistant Professor, Department of Surgery, Gujarat Adani Institute of Medical Science, Bhuj, Gujarat, India.

E-mail: mahalaxmipillai@gmail.com

Received: 02 June 2020

Revised: 13 July 2020

Accepted: 22 July 2020

Published: 27 December 2020

\section{Introduction}

The peritoneal cavity is the chief cavity in the body. The peritoneal membrane is expediently alienated into two parts the visceral peritoneum adjoining the viscera and the parietal peritoneum lining the erstwhile surfaces of the cavity. The parietal segment is opulently supplied with nerves and, when irritated, roots severe pain that is precisely contained to the affected region. The visceral peritoneum, in contrast, is inadequately supplied with nerves and its annoyance grounds pain that is typically inadequately restricted to the midline. ${ }^{[1-5]}$

The term "peritonitis" comes from Greek word peritonaion peritoneum means "Abdominal membrane" and -it is means "inflammation". The majority cases of peritonitis are due to an incursion of the peritoneal cavity by bacteria, in order that when the term 'peritonitis' is utilized with no qualification, acute bacterial peritonitis is frequently implicit. ${ }^{[6-8]}$

After diagnosis through various pathological parameters and radiological aids treatment protocols are decided i.e. conser- vative or operative. Treatment includes primarily resuscitation of the general condition of the patient with fluids, antibiotics, analgesics and vasopressors if indicated. This was followed by treatment of the specific cause of the disease which included drainage of abscess or removal of the particular organ or repair of the perforation. This operative intervention was being done in a conventional manner for a long time but with the advent of laparascopic techniques into the field of surgery; many cases were dealt with minimally invasive technique only and treated.

\section{Subjects and Methods}

The observational, continuous, prospective, single centre study was carried out at Gujarat Adani Institute of Medical Science at GK General Hospital Bhuj. The study was conducted for a total duration of 27 months from October 2017- December 2019 (Patients were enrolled in the study and followed up till the day of admission to the day of the discharge). Total 100 patients are enrolled in the study but there were no intervention done. We compare the outcomes 
in terms of postoperative pain, removal of ryles tube, urinary catheter, drains, early ambulation and duration of hospital stay.

\section{Statistical analysis}

The data were analyzing using SPSS version 15 (SPSS Inc., Chicago, Illinois, USA).

\section{Results and Discussion}

In current study, 50 patients of peritonitis were managed laparoscopically and 50 patients of peritonitis were supervising by open laparotomy approach. Mean age of patients in this research was 40.5 years, which was somewhat lesser than the mean age of 46.5 years as per study carry out by Ahmed et al, ${ }^{[9]}$ and the mean age of 41.6 years as per study performed by Munish Trehan et al. Majority of the patient in this study were in age group of 41 to 50 years $(40 \%)$ followed by 21 to 30 years $(23 \%)$ and 31 to 40 years of age $(23 \%)$ followed by 51 to 60 years $(14 \%)(n=100)$. In laparoscopic management group mean age was 35.37 year where in conventional management group it was 37.06 year. In this study, $62 \%$ cases constitute males and $38 \%$ females. The ratio of male: female was 1.6:1. Separately in both groups ratio of male to female was $3: 2$ in laparoscopic management \& 1.7:1 in conventional management group.

In this study maximum patients were diagnosed as having pre pyloric peptic (pyloric with antral perforation) perforation (45\%) followed by jejunal perforation (17\%). Ileal perforation constituted $12 \%$ of all cases. Duodenal perforation constituted $10 \%$ of all cases. Ascending colon perforation constituted $9 \%$ of all cases. Descending colon perforation constituted $6 \%$ of all cases. Sigmoid colon perforation constituted for only $1 \%$ of all cases. Similar type demographic details were founded in other studies like Ahmed Khan et al. ${ }^{[9]}$ In this study $85 \%$ of cases were diagnosed preoperatively by radiographs, ultrasonography and CT scan findings. Investigative accurateness of laparoscopic examination is accounted to be around 90 percent in findings of the research carry out by Navez et al, ${ }^{[10]}$ too as elevated as $98 \%$ as reported by Kirshtein. ${ }^{[11]}$ Total $72.3 \%$ of patients were analysed preoperatively on account of radiological investigations as contrast to study by Lagoo $\mathrm{S}$ et al. In this study successful laparoscopic surgery without conversion was done in $92 \% .{ }^{[12,13]}$ In research performed by So JB et $\mathrm{al}^{[14]}$ this rate was $88 \%$. In these study total 4 cases of laparoscopic managed group needed to convert in open including 2 duodenal perforation cases, 1 sigmoid colon perforation case and 1 ascending colon perforation case. These cases needed to convert to open because of dense adhesions, large perforation and limited visualization with laparoscope.

Fifteen subjects with past record of major abdominal surgery undergo simply laparoscopic surgery. Just 3 patients undergo transfer of laparoscopic surgery into open surgery due to earlier surgery.

In this study post-operative pain was evaluated by numerical rating scale (NRS) ${ }^{[8]}$ which ranges from 0 to 10 . In this scale 0 means no pain at all and 10 means severe excruciating pain. As discussed in result, average pain in 3 post-operative days was less in severity in laparoscopic management group as compare to open management group. Total $45 \%$ cases $(n=45)$ were diagnosed as peptic perforation out of them $53.3 \%$ (24 out of 45 ) was managed by laparoscopy and $46.6 \%$ (21 out of 45$)$ by conventional open management which are $45.6 \%$ (57 out of 125 ) in laparoscopic group and $4.3 \%$ (1 out of 23 ) as per study of Yeom et al, ${ }^{[15]}$ Conversion to laparotomy was not required in any of the patients to clarify the diagnosis. The mean age of patients was 42.8 (range 21-55) years [Male $29 \&$ Female 13]; these also include accidental injury on stomach. Out of these 30 patients had a past history of significant acid peptic disease, 2 had diabetes mellitus type $2 \& 12$ had a history of previous operative intervention including tubal ligation which was significantly related to peptic perforation).

All patients were operated by primary closure of perforation with omentopexy. The mean operative time recorded was 98.66 (range, 60-170) minutes separately which was average 108.13 minutes in laparoscopic management and 88.25 minutes in conventional management, which is significantly less in conventional management. This average operative time is similar to study of Lee et al in which average operative time in laparoscopic group was 104 minutes and in open group is 75 minutes. ${ }^{[10]}$ Majority of the perforation size recorded intra-operatively was $0.5 * 1 \mathrm{~cm}$ range in $30 \%$ cases which is similar to study done by Lee et al., in which average size of perforation was $5 \mathrm{~mm} .{ }^{[16]}$ The mean hospital stay was 5.04 days; separately average 4.68 day in laparoscopic management and 5.7 in conventional management, which was significantly shorter in laparoscopic management. These is similar to study of Lee et al. in which there was average hospital stay of 4 days in laparoscopic group and 5 days in open group. ${ }^{[16]}$

The mean time duration of Ryle's tube removal was 2.16 days separately which was average 1.95 days in laparoscopic management and 2.5 days in conventional management which was significantly less in laparoscopic management. Average duration of nasogastric decompression is almost similar to study of Bertleff et al. which were 2 day in laparoscopic group and 3 days in open groups. ${ }^{[17]}$ The average time to start oral feeding was 3.27 days separately which was 2.86 days in laparoscopic \& 3.9 in conventional management, which was statistically significant between both groups, shorter in laparoscopic management group. The mean time of passing stool post operatively was 4.23 days separately which was average 3.9 days in laparoscopic management and 4.8 days in conventional management. This time period was shorter in laparoscopic management as compare to conventional 
management. The average time to removal of Morison pouch drain, pelvic drain was 2.38 and 4.14 days respectively which was $2.18 \& 3.77$ in laparoscopic and $2.6 \& 4.55$ in conventional management respectively which was significantly less in laparoscopic management.

In this study 4 patient of peptic perforation were complained of wound complication like mild to moderate serous discharge or seroma formation; out of which in laparoscopic management group 1 case in this study and 0 cases in study of Lee et al. $\&$ in open laparotomy group 3 cases in this study and 6 cases in study of Lee et al. ${ }^{[16]}$ In both studies wound complications were more in open laparotomy group. There was no any long term follow up complain in laparoscopic management patients but 12 patients had complain of weakness or mild to moderate pain at stitch line in open management group. Total 10 patients out of 100 were diagnosed by duodenal perforation. 5 out of 10 patients were managed by laparoscopic $\& 5$ were managed by conventional management; 2 patients had to be converted from laparoscopic to open management for better approach and limited view in laparoscope. They are 20 out of 52 in laparoscopic group and 14 out of 49 as per study of Bertleff et al. ${ }^{[17]}$ The mean time of removal of Ryle's tube, removal of Morison pouch drain, removal of pelvic drain, starting of oral feeding, passing stool was 2, 2, $4,3,5$ days respectively in laparoscopic management group which were 2, 3, 4, 4, 5 days in open management group. Thus oral intake can be started earlier in laparoscopic group. The average hospital reside was 5 days in laparoscopic group and 6 days in open management group. Thus average hospital stay is less in laparoscopic group. Parallel observations were noted in study of Lee et al, ${ }^{[16]}$ and Bertleff et al. ${ }^{[17]}$ Total 29 patients out of 100 were diagnosed as small intestinal perforation. 17 cases out of 29 had jejunal perforation and 12 cases out of 29 had ilieal perforation. 12 out of 29 patients were managed by laparoscopic \& 17 out of 29 patients were managed by conventional open management. The mean time of removal of Ryle's tube, removal of Morison pouch drain, removal of pelvic drain, starting of oral feeding, passing stool was lesser in laparoscopic group followed by open management group. Thus oral intake can be started earlier in laparoscopic group. Post-operative ileus was developed in 2 cases of laparoscopic group and in 7 cases of open laparotomy group in this study. More chances of post-operative ileus in open laparotomy group of this study were due to pain in abdomen and less ambulation. Incidences of abscess formation, urinary tract infection, and respiratory tract complication like pneumonia were higher in open laparotomy group in this study. Total 16 patients out of 100 were diagnosed as large intestinal perforation. 9 cases out of 16 was ascending colon perforation and 6 cases out of 16 was descending colon perforation and 1 case was sigmoid colon perforation. 9 out of 16 patients were managed by laparoscopic \& 7 out of 16 patients were managed by conventional open management. 2 out of 16 patients were needed to convert from laparoscopic to open method. The mean time of removal of Ryle's tube, removal of Morison pouch drain, removal of pelvic drain, starting of oral feeding, passing stool was lesser in laparoscopic group then open management group. Thus oral intake can be started earlier in laparoscopic group. ${ }^{[18]}$

The standard operative time was lesser in open management group. Average hospital stay was 9 days in laparoscopic group and 11 days in open group in distinction to $7.2 \pm$ 4.1 days as in laparoscopic group in research performed by Ferdinando Agresta et al. ${ }^{[19]}$ Thus average hospital stay is less in laparoscopic group. Post-operative ileus was developed in 2 cases of laparoscopic group and in 5 cases of open laparotomy group in this study. More chances of postoperative ileus in open laparotomy group of this study were due to pain in abdomen and less ambulation. Surgical wound infection was developed in 2 cases of laparoscopic group and in 6 cases of open laparotomy group in this study.

Going on the findings of the present study and comparison with similar studies, it is observed that laparoscopic surgery is appropriate to surgery for peritonitis. It is confirmed that the austerely insidious approach permits superior diagnostic and curative precision, superior short- and long-term results and a quicker postoperative recovery. Laparoscopy offers sufficient visualization of the whole abdomen and pelvic cavity in the analysis of acute abdomen secondary to perforation leading to peritonitis. though operative times is frequently longer than open surgery, in presence of qualified surgeons with appropriate assortment of stable patients, laparoscopic management appears to be a realistic, secure and effectual surgical option in case peritonitis. However laparoscopic management requires skilled experience surgeons and laparoscopic set up. The threat of high intra-abdominal pressure due to pneumoperitoneum can be reduced by maintaining intraperitoneal pressure on or below $12 \mathrm{mmHg}$. Conversion to open laparotomy should be considered as a rational decision and not as a complication of the minimally invasive procedures. On the basis of our results there is significant decrease post-operative pain in abdomen in laparoscopic management group as compare to open management group. Post-operative nasogastric tube removal and abdominal drain removal is earlier in laparoscopic management group as compare to open management group in this study. In this study, in all patients of Conclusion Page 68 laparoscopic management group it was possible to start oral food intake earlier then in open management group. In this study all patients of laparoscopic management group ambulation was earlier with less post-operative complications as compare to open management group. Thus laparoscopic management of peritonitis, particularly for peptic and small intestinal perforation is more feasible than open laparotomy when patient is vitally and haemodynamically stable. However if laparoscopic surgery becomes difficult owing to 
a patient's condition or surgeon's lack of experience, the surgeon should not hesitate to convert to open surgery.

\section{Conclusion}

Results of the study shows that laparoscopic management is better than the conventional management as there was a fewer postoperative complications as compare to conventional management in terms of less postoperative complain like postoperative pain, earlier removal of Ryle's tube, earlier removal of abdominal drains, earlier oral intake, earlier ambulation of patient, suture line infection, less respiratory complications like pneumonia, less urinary tract infections, less postoperative ileus, less intra-abdominal abscess and shorter hospital stay of the patients. However in laparoscopic management of peritonitis, operative time is longer than open conventional management and higher surgical skills are required in laparoscopy as compare to open laparotomy surgery.

\section{References}

1. Struller F, Weinreich FJ, Horvath P, Kokkalis MK, Beckert S, Königsrainer A, et al. Peritoneal innervation: embryology and functional anatomy. Pleura Peritoneum. 2017;2(4):153-161. Available from: https://dx.doi.org/10.1515/pp-2017-0024.

2. Jhobta RS, Attri AK, Kaushik R, Sharma R. Spectrum of perforation peritonitis in India-review of 504 consecutive cases. World J Emerg Surg. 2006;1(26):1-4. Available from: https: //doi.org/10.1186/1749-7922-1-26.

3. Wu AM, Zhang K, Li XL, Cheng XF, Zhou TJ, Du L, et al. The compression of L5 nerve root, single or double sites?radiographic graded signs, intra-operative detect technique and clinical outcomes. Quant Imaging Med Surg. 2018;8(4):383390. Available from: https://dx.doi.org/10.21037/qims.2018. 05.08.

4. Charles H, Williams PKN, Ronan O, Connell A, Mccaskie. The peritoneum, omentum, mesentery and retroperitoneal space; 2018.

5. Michailova KN, Wassilev WA, Kühnel W. Features of the peritoneal covering of the lesser pelvis with special reference to stomata regions. Ann Anat. 2005;187(1):23-33. Available from: https://dx.doi.org/10.1016/j.aanat.2004.05.002.

6. Suzuki K, Horigome I, Shishido Y, Chiba S, Miyazaki M. Peritoneal dialysis-associated peritonitis caused by gram-negative bacteria: characteristics similar to spontaneous bacterial peritonitis? Adv Perit Dial. 1999;15:197-200.

7. Leivonen MK, Haglund $\mathrm{CH}$, Nordling SFA. Helicobacter pylori infection after partial gastrectomy for peptic ulcer and its role in relapsing disease. Eur J Gastroenterol Hepatol. 1997;9(4):373-374. Available from: https://dx.doi.org/10. 1097/00042737-199704000-00010.

8. Boey J, Wong J, Ong GB. A Prospective Study of Operative Risk Factors in Perforated Duodenal Ulcers. Ann Surg . 1982;195(3):265-269. Available from: https://dx.doi.org/10.
1097/00000658-198203000-00004.

9. Sangrasi AK, Talpur KAH, Kella N, Laghari AA, Abbasi MR, Qureshi JN. Role of laparoscopy in peritonitis. PaK J Med Sci. 2013;29(4):1028-1032. Available from: https://dx.doi.org/10. 12669/pjms.294.3624.

10. Navez B, d'Udekem Y, Cambier E, Richir C, de Pierpont B, Guiot P. Laparoscopy for management of nontraumatic acute abdomen. World J Surg. 1995;19(3):382-386. Available from: https://dx.doi.org/10.1007/bf00299164.

11. Kirshtein B, Roy-Shapira A, Lantsberg L, Mandel S, Avinoach E, Mizrahi S. The use of laparoscopy in abdominal emergencies. Surg Endosc. 2003;17(7):1118-1124. Available from: https://dx.doi.org/10.1007/s00464-002-9114-1.

12. Lau WY, Leung KL, Zhu XL, Lam YH, Chung SCS, Li AKC. Laparoscopic repair of perforated peptic ulcer. Br J Surg . 1995;82(6):814-816. Available from: https://dx.doi.org/10. 1002/bjs. 1800820630 .

13. Lagoo S, Mahon RLM, Kalkharu M, T NPP, Eubanks S. The sixth decision regarding perforated duodenal ulcer. JSLS. 2002;6:359-68.

14. Sø JBY, Kum CK, Fernandes ML, Goh P. Comparison between laparoscopic and conventional omental patch repair for perforated duodenal ulcer. Surg Endo. 1996;10(11):1060-1063. Available from: https://dx.doi.org/10.1007/s004649900240.

15. Yeom S, Kim MS, Park S. Comparison of the outcomes of laparoscopic and open approaches in the treatment of periappendiceal abscess diagnosed by radiologic investigation. J Laparoendosc Adv Surg Tech. 2014;24(11):762-769. Available from: https://doi.org/10.1089/lap.2014.0224.

16. Lee FYJ, Leung KL, Lai PBS, Lau JWY. Selection of patients for laparoscopic repair of perforated peptic ulcer. Br J Surg. 2001;88(1):133-136. Available from: https://dx.doi.org/10. 1046/j.1365-2168.2001.01642.x.

17. Bertleff MJOE, Stegmann T, Liem RSB, Kors G, Robinson PH, Nicolai JP, et al. Comparison of Closure of Gastric Perforation Ulcers With Biodegradable Lactide-Glycolide-Caprolactone or Omental Patches. JSLS. 2009;13(4):550-554. Available from: https://dx.doi.org/10.4293/108680809x12589998404362.

18. Sinha R, Sharma N, Joshi M. Laparoscopic repair of small bowel perforation. JSLS. 2005;9(4):399-402.

19. Agresta F, Ciardo LF, Mazzarolo G, Michelet I, Orsi G, Trentin G. World J Emerg Surg. 2006;24:1-9.

Copyright: (C) the author(s), 2020. It is an open-access article distributed under the terms of the Creative Commons Attribution License (CC BY 4.0), which permits authors to retain ownership of the copyright for their content, and allow anyone to download, reuse, reprint, modify, distribute and/or copy the content as long as the original authors and source are cited.

How to cite this article: Santoki NR, Pillai M, Rao G. Comparative Study of Role of Laparoscopic Vs Conventional Management in Peritonitis. Acad. J Surg. 2020;3(2):21-24.

DOI: dx.doi.org/10.47008/ajs/2020.3.2.6

Source of Support: Nil, Conflict of Interest: None declared. 